Bioanalysis: Advanced Materials, Methods, and Devices

Series Editor: Tuan Vo-Dinh

- Michael W. Collins

Carola S. König Editors

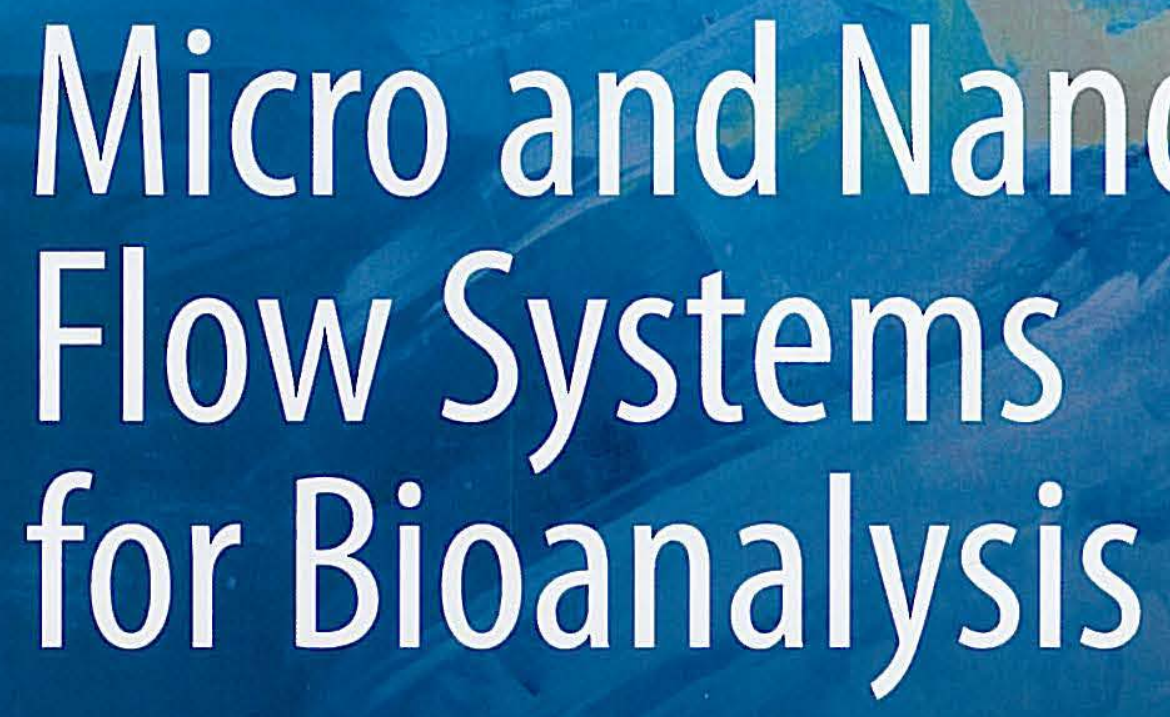

Springer 


\section{Editors}

Michael W. Collins

School of Engineering and Design

Brunel University

London, UK
Carola S. König

Brunel Institute for Bioengineering

Brunel University

London, UK

ISBN 978-1-4614-4375-9

ISBN 978-1-4614-4376-6 (eBook)

DOI 10.1007/978-1-4614-4376-6

Springer New York Heidelberg Dordrecht London

Library of Congress Control Number: 2012951672

(C) Springer Science+Business Media New York 2013

This work is subject to copyright. All rights are reserved by the Publisher, whether the whole or part of the material is concerned, specifically the rights of translation, reprinting, reuse of illustrations, recitation, broadcasting, reproduction on microfilms or in any other physical way, and transmission or information storage and retrieval, electronic adaptation, computer software, or by similar or dissimilar methodology now known or hereafter developed. Exempted from this legal reservation are brief excerpts in connection with reviews or scholarly analysis or material supplied specifically for the purpose of being entered and executed on a computer system, for exclusive use by the purchaser of the work. Duplication of this publication or parts thereof is permitted only under the provisions of the Copyright Law of the Publisher's location, in its current version, and permission for use must always be obtained from Springer. Permissions for use may be obtained through RightsLink at the Copyright Clearance Center. Violations are liable to prosecution under the respective Copyright Law.

The use of general descriptive names, registered names, trademarks, service marks, etc. in this publication does not imply, even in the absence of a specific statement, that such names are exempt from the relevant protective laws and regulations and therefore free for general use.

While the advice and information in this book are believed to be true and accurate at the date of publication, neither the authors nor the editors nor the publisher can accept any legal responsibility for any errors or omissions that may be made. The publisher makes no warranty, express or implied, with respect to the material contained herein.

Printed on acid-free paper

Springer is part of Springer Science+Business Media (www.springer.com) 


\title{
Chapter 9 \\ Confocal Micro-PIV/PTV Measurements of the Blood Flow in Micro-channels
}

\author{
Rui Lima, Takuji Ishikawa, Yohsuke Imai, and Takami Yamaguchi
}

Abstract The development of optical experimental techniques has contributed to obtaining explanations of the behaviour of blood flowing in micro-channels. Although past results have been valuable, detailed studies on the flow properties of in vitro blood in micro-channels have been limited by several technical factors such as poor spatial resolution and difficulty in obtaining quantitative detailed measurements at such small scales. In recent years, due to advances in computers, optics, and digital image processing techniques, it has become possible to combine both particle image velocimetry (PIV) and particle tracking velocimetry (PTV) methods with confocal microscopes. As a result, this combination has greatly increased the resolution of conventional micro-PIV/PTV systems and consequently provided additional detailed description on the motion of blood cells not obtainable by traditional methods. In this chapter the most relevant theoretical and technical issues related to both conventional and confocal micro-PIV/PTV methods are discussed. Additionally, the most recent studies on the blood flow behaviour in micro-channels obtained by our confocal micro-PIV/PTV system are also reviewed.

\footnotetext{
R. Lima (国)

DTM, ESTiG/IPB, Braganca Polytechnic, C. Sta. Apolonia, Braganca 5301-857, Portugal

CEFT, FEUP, Porto University, R. Dr. Roberto Frias, Porto 4200-465, Portugal

e-mail: ruimec@ipb.pt

T. Ishikawa $\cdot$ Y. Imai

School of Engineering, Tohoku University, 6-6-01 Aoba, Sendai, 980-8579, Japan

T. Yamaguchi

School of Biomedical Engineering, Tohoku University, 6-6-01 Aoba, Sendai 980-8579, Japan
}

M.W. Collins and C.S. König (eds.), Micro and Nano Flow Systems 


\subsection{Introduction}

Human blood is a complex fluid composed mainly of suspended deformable red blood cells (RBCs) within the plasma flow, which are responsible for the supply of oxygen and nutrients to, and removal of carbon dioxide and metabolic wastes from tissues. Phenomena of blood flow in microcirculation depend on several combined effects such as cell deformability, flow shear rates and vessel wall, together with micro-scale biochemical and physiological factors. Since the availability of microscopic techniques scientists have started using optical methods mainly because they are less invasive for measuring the flow field. However, the fact that measurements of blood flow in the microcirculation need to be performed at very small scales has limited the number of flow measurement techniques suitable for this purpose. For instance, MRI and ultrasonography are not suitable for obtaining quantitative flow information in micro-vessels mainly due to their poor spatial resolution. The majority of the works performed in the past to measure blood flow in microvessels and micro-channels are double-slit photometry $[4,12]$, video microscopy and image analysis $[2,6,13-15,41,43]$ and laser-Doppler anemometry $[5,7,9,16,49]$. Recently, the considerable progress in computing capability, optics, high-speed imaging and image processing techniques have made it possible to successfully combine a conventional PIV system with an inverted epifluorescent microscope $[19,39,45,51]$. This combination, known as micro-PIV, has greatly increased the resolution of conventional PIV; as a result, this technique has gained widespread use to investigate blood flow behaviour in both micro-channels and micro-vessels. Sugii and his co-workers, by using a conventional micro-PIV system, have used red blood cells as tracer markers to measure their velocities in both straight [46] and bifurcated arterioles [40] and they found that the velocity profiles were markedly blunt in the central region. Later they measured both tracer particles and RBCs through a $100 \mu \mathrm{m}$ glass capillary and they reported that by using in vitro blood with $20 \%$ hematocrit (Hct) the velocity profiles were parabolic [47]. More recently, by using liposome tracer particles the blood-plasma velocity has been measured in the beating heart of a chicken embryo [50]. Kim and Lee [18] have analysed the flow behaviour of blood through a circular opaque micro-channel by using an X-ray PIV technique. Their measurements have shown typical non-Newtonian flow characteristics of blood such as yield stress and shear-thinning effects. Generally, most of the findings relating to blood flow dynamics using conventional micro-PIV have yielded conflicting results. In addition, such measurements do not give detailed information on the micro-scale flow behaviour of RBCs in micro-vessels. Hence, there is a need to apply other kinds of optical methods better able to obtain further insight into the complex flow behaviour of blood in the microcirculation.

Recently, the ability to combine both conventional particle image velocimetry (PVI) and particle tracking velocimetry (PTV) systems with a spinning disc confocal microscope (SDCM) has proven an extremely powerful technique to obtain detailed qualitative and quantitative measurements of in vitro blood flowing 
through micro-channels. The current chapter will present the most relevant theoretical and technical issues related to both methods and also a comparison between them. Additionally, our most recent confocal micro-PIV/PTV results of blood flow behaviour in both glass and polydimethylsiloxane (PDMS) micro-channels are reviewed.

\subsection{PIV/PTV Principles}

\subsubsection{Calculation Methodology}

The principle of calculating several physical parameters (displacement, velocity, shear stress, etc.) related to fluid mechanics is common to both PIV and micro-PIV. The traditional way consists of measuring the displacement of fluorescent tracer particles flowing within the working fluid. However, to measure physiological fluids, such as blood, it is also common to use labelled blood cells as natural tracer particles. By applying a powerful light source, the tracer particles or cells of interest are illuminated and as a result objects with a known time interval $(\Delta t)$ can be recorded by a high speed camera. By using a short $\Delta t$, it can be assumed that the magnitude and direction of the object velocities are constant. As a result, the location of a particle on two consecutive images can be used to estimate its instantaneous velocity as:

$$
\begin{aligned}
& \vec{u}=\frac{\vec{x}_{t+\Delta t}^{i}-\vec{x}_{t}^{i}}{\Delta t} \\
& \vec{v}=\frac{\vec{y}_{t+\Delta t}^{i}-\vec{y}_{t}^{i}}{\Delta t}
\end{aligned}
$$

where $u$ and $v$ are respectively the velocity components of the particle in the $x$ and $y$ direction. Figure 9.1 shows an overview of the PIV/PTV principle.

The approach used to calculate the velocity of one particle can be extended to the entire flow field of interest. In microfluidics it is common practice to average the instantaneous velocities over a large number of recorded image pairs ( $N$ usually greater than 20). Hence, the time-average mean velocity vector of the flow can be defined as

$$
\begin{aligned}
& \vec{U}=\frac{1}{N} \sum_{t=1}^{N} \vec{u}_{t} \\
& \vec{V}=\frac{1}{N} \sum_{t=1}^{N} \vec{v}_{t}
\end{aligned}
$$




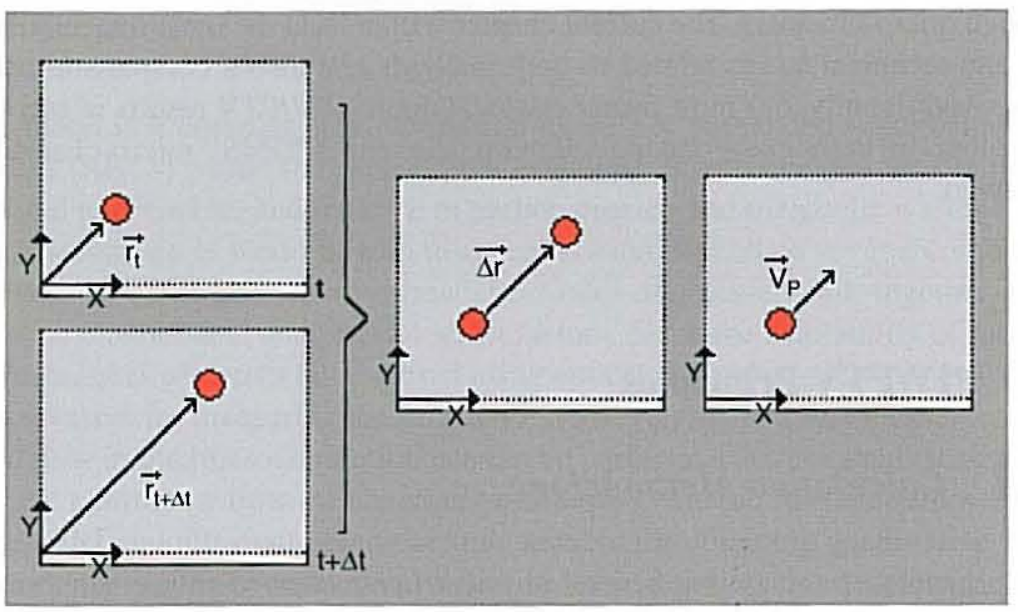

Fig. 9.1 Principle for both PIV and PTV (adapted from [24])

where $N$ is the number of instantaneous velocity measurements, $u$ and $v$ are the time-average mean velocity components of the particle in the $x$ and $y$ directions, respectively.

\subsubsection{PIV vs. PTV Methods}

The density of trace particles in the images determines the most suitable PIV methodology to calculate the velocity fields. For high concentration of particles, i.e. the interrogation window contains at least three particles, the method is known as high-image-density PIV mode (see Fig. 9.2) [1]. Several researchers consider this method as the most reliable way of determining the velocity field which is estimated by using a statistical technique known as cross-correlation. It is described with much more detail elsewhere [24,27], the overall method being known as PIV cross-correlation, or simply PIV.

In some specific situations such as physiological fluids with high concentrations of cells, the amount of tracer particles captured within the fluid is often low (see Fig. 9.2). One way to overcome the problem of this particular condition is to measure the displacements by tracking individual particles or cells (see Fig. 9.3). This low-image-density PIV methodology is often referred to as particle tracking velocimetry (PTV) or as single particle tracking (SPT) $[1,44]$. By using this method detailed quantitative information can be obtained on the motion of particles and cells flowing within the working fluid. PTV is, however, limited in its ability to compute automatically particle trajectories, especially when there are multiple collisions of particles or cells. One way to overcome this limitation is by using manual tracking methods. 


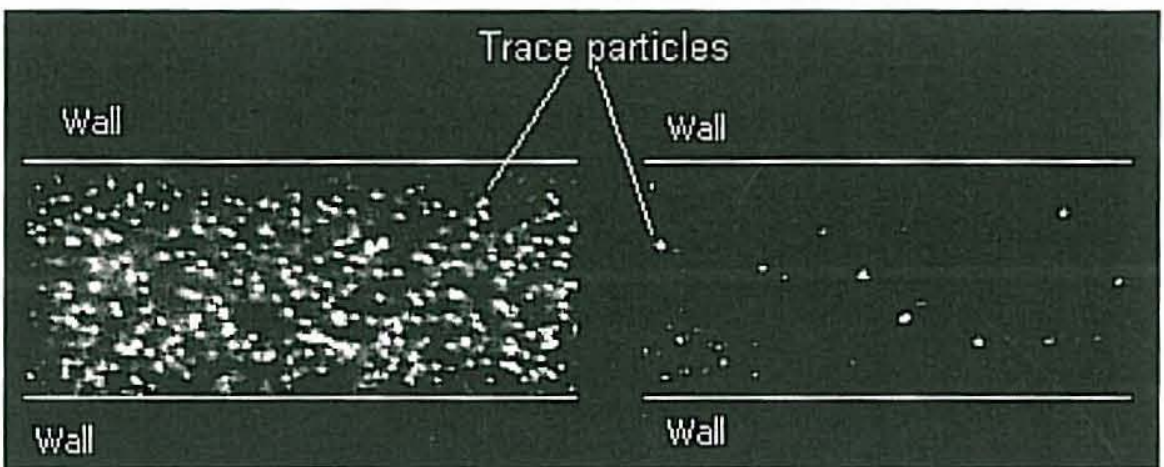

Fig. 9.2 Confocal high density image with pure water (left image) and confocal low density image with blood $30 \%$ Hct (right image)
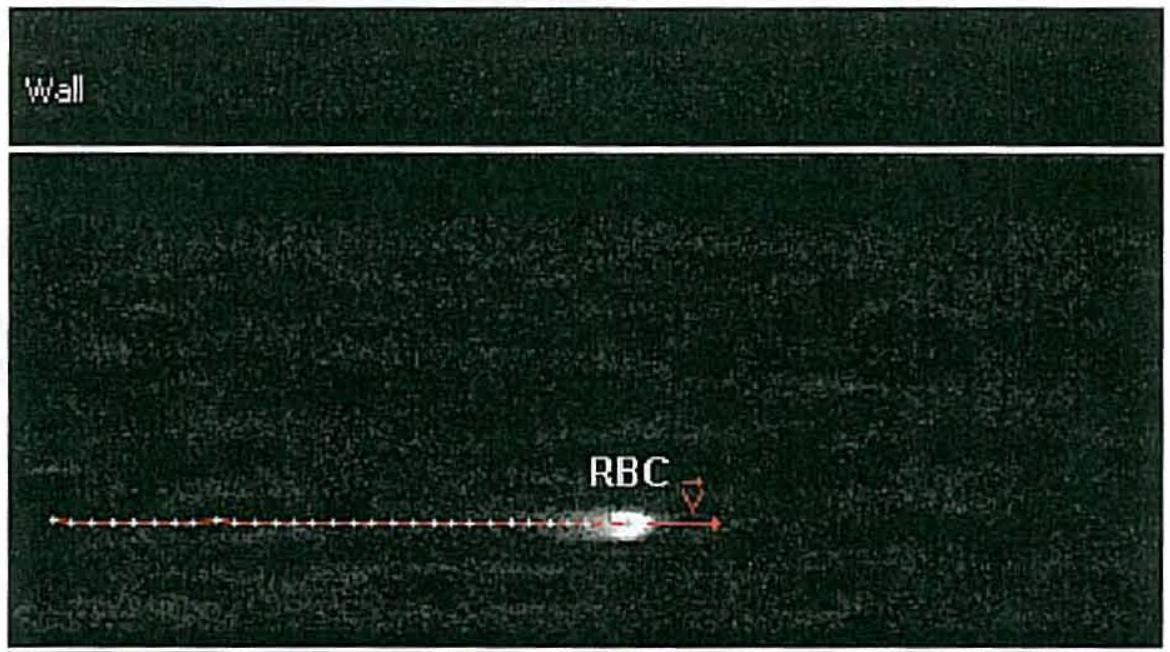

\section{wall}

Fig. 9.3 Trajectory of RBC flowing in a micro-channel by using a manual particle tracking technique from ImageJ 


\subsection{Confocal Micro-PIV/PTV System}

\subsubsection{Conventional Micro-PIV System}

A conventional micro-PIV system consists essentially of a microscope, an objective lens, optical filters, a light source for flow illumination and a high speed camera. Figure 9.4 gives a schematic illustration of a conventional micro-PIV system. Briefly, the light enters the microscope and is reflected $90^{\circ}$ upwards by a dichromatic mirror to be transmitted through the objective lens which illuminates the entire flow volume. The objective lens collects the light emitted from the particles which goes back to the dichromatic mirror and to a high speed camera to record the signals from the trace particles. Finally, the recorded images are transferred to a computer to use a PIV post-processing method such as the cross-correlation technique. It is worth mentioning that the resolution of a micro-PIV system is influenced by several factors such as: out-of-focus particle images due to the volume illumination, and density and size of the tracer particles. By using a confocal system, most of the out-of-focus particles can be removed, consequently reducing the errors generated in the velocity field measurements.

\subsubsection{Confocal Micro-PIV System}

A confocal micro-PIV system consists usually of an inverted microscope combined with a confocal scanning unit (CSU), a high resolution objective lens, a high power

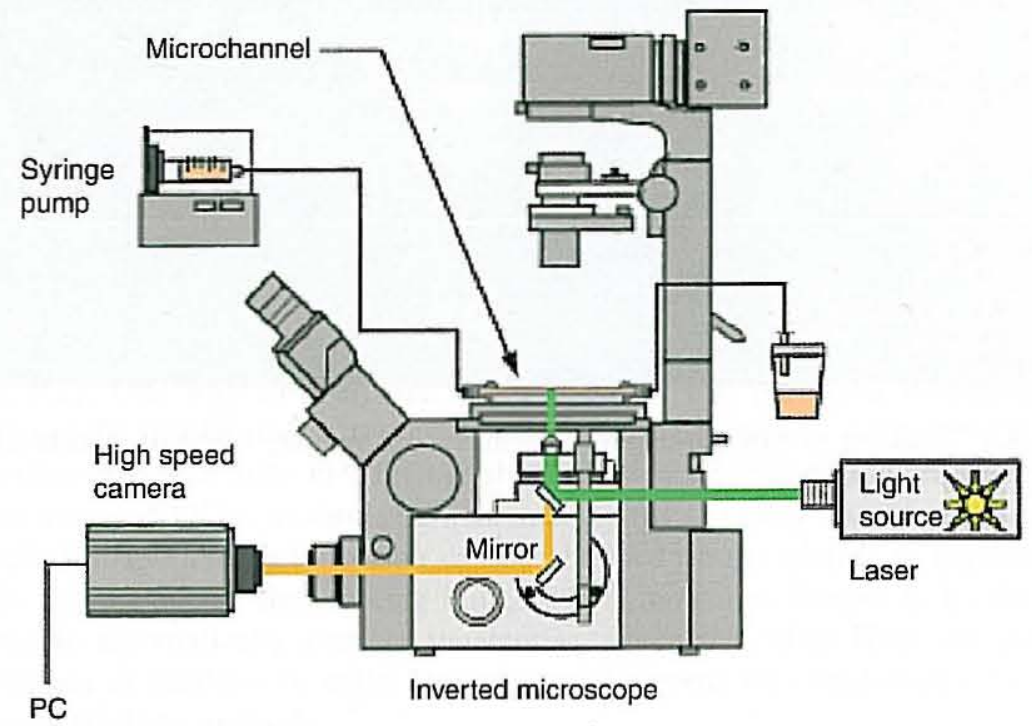

Fig. 9.4 Experimental setup of a conventional micro-PIV system. 
jective amera. iystem. dichrotes the articles ord the id to a $n$ techuenced illumi1, most errors

nbined power

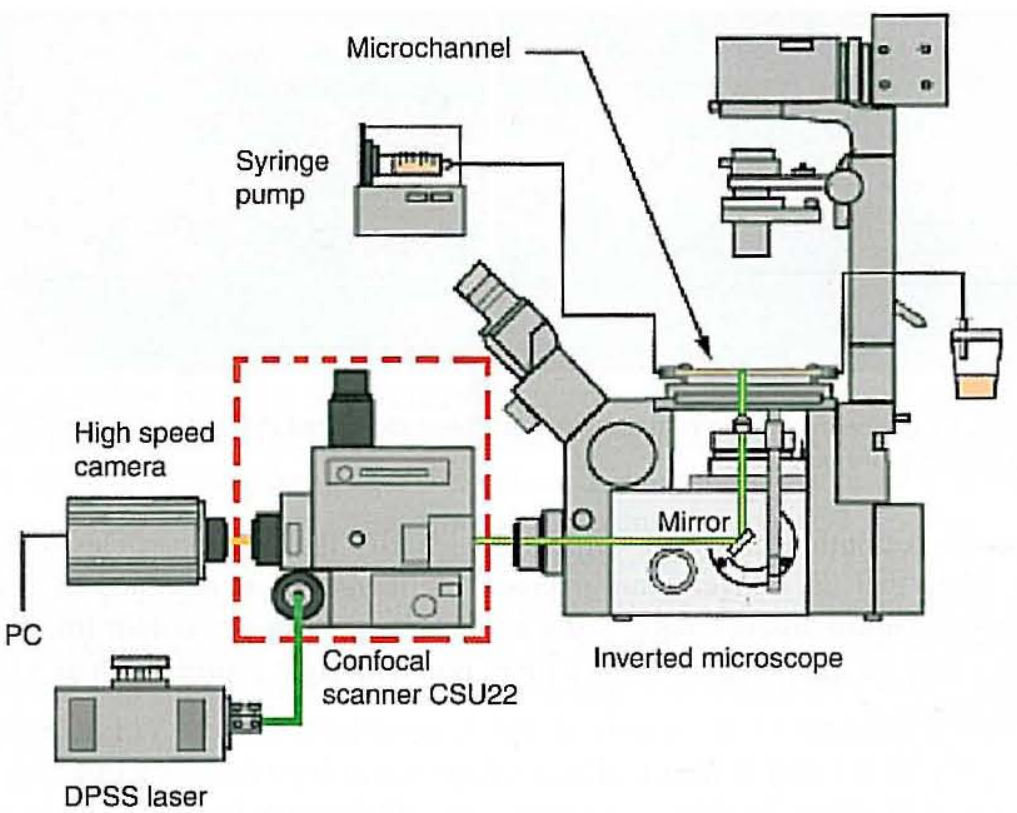

Fig. 9.5 Experimental setup of a confocal micro-PIV system

light source (usually laser) and a high speed camera, as shown in Fig. 9.5. In a confocal system the light enters the CSU and then is conducted to the microscope to illuminate the sample from below the microscope stage. The light emitted from the fluorescent trace particles goes back into the CSU and then to a high-speed camera to capture the confocal images.

\subsubsection{Comparison Between Conventional and Confocal Micro-PIV}

Figures 9.4 and 9.5 show the main components of both conventional and confocal micro-PIV systems. It is clear that the main difference between the two systems is the existence of a CSU in the confocal system. A study to compare the systems was performed under the same flow conditions. The flow measurements were performed in a $100 \mu \mathrm{m}$ glass square micro-channel where pure water seeded with $0.15 \%$ of tracer particles was pressure driven by means of a syringe pump.

Figure 9.6, clearly demonstrates that by using a CSU it is possible to obtain much clearer image definition of the individual trace particles. Hence, a confocal system reduces the out-of-focus background noise and therefore increases the contrast and definition of an image. By contrast, images recorded by the conventional system were largely blurred, since the out-focus-light reduces contrast and 

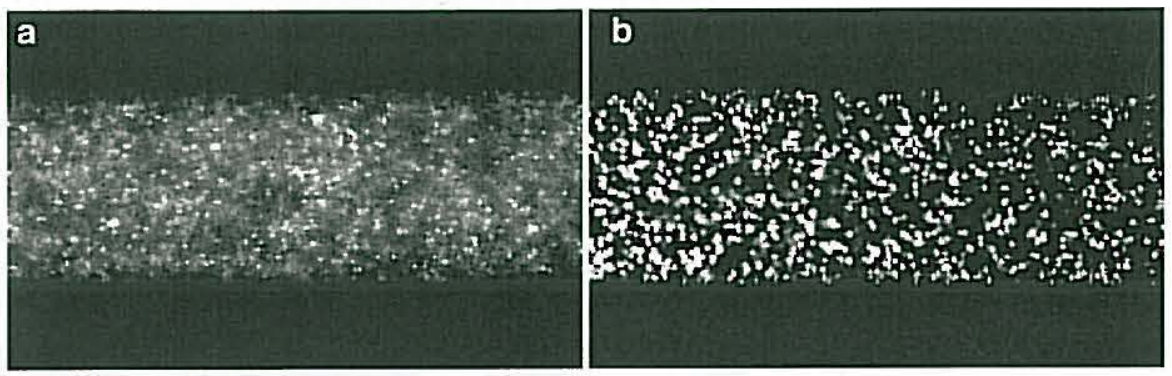

Fig. 9.6 Comparison of particle images from (a) conventional and (b) confocal micro-PIV system at $20 \mu \mathrm{m}$ depth for pure water

decreases resolution making it difficult to identify the tracer particles within the flow. Note that the conventional microscopic images were obtained by using an epifluorescent microscope equipped with a mercury lamp and colour filters. These images may be improved by using a more powerful light source, such as a laser or metal halide.

\subsection{Confocal Micro-PIV/PTV Measurements and Results}

This section shows the most recent studies on blood flow behaviour in microchannels performed by our confocal micro-PIV/PTV system. The main emphasis is on the confocal micro-PIV/PTV results obtained from both glass and polydimethylsiloxane (PDMS) micro-channels.

\subsubsection{Working Fluids, Micro-channels, Experimental Set-up and Image Analysis}

Confocal micro-PIV measuements were performed with different working fluids such as physiological saline (PS) with fluorescent trace particles, and in vitro blood containing trace particles and human RBCs with a hematocrit (Hct) up to $20 \%$. Confocal micro-PTV experiments were carried out also with different working fluids such as dextran $40(\mathrm{Dx}-40)$ containing about $3 \%$ Hct up to $35 \%$ Hct of human RBCs. For this latter system, rather than employing fluorescent particles labelled RBCs were used to study the flow in micro-channels. A full description of the procedure for labeling human RBCs can be found in Lima et al. [28].

For both confocal systems experiments were performed with different kinds of micro-channels, such as $100-\mu \mathrm{m}$ and $50-\mu \mathrm{m}$ circular and square borosilicate glass micro-channels as fabricated by Vitrocom (Mountain Lakes, NJ, USA) [23,25,31]. By using a soft lithographic technique it was also possible to fabricate rectangular 
polydimensiloxane (PDMS) micro-channels with complex geometries such as stenoses, bifurcations, confluences and hyperbolic contractions [11,20-22,27,34-36,52,53]. Additionally, by using a wire casting technique [29] it was possible to fabricate $75-\mu$ $\mathrm{m}$ circular PDMS micro-channels.

Generally both confocal systems used in our flow studies consisted of an inverted microscope (IX71; Olympus, Tokyo, Japan) combined with a confocal scanning unit (CSU22; Yokogawa, Tokyo, Japan), a diode-pumped solid state (DPSS) laser (Laser Quantum Ltd., Stockport, UK) and a high-speed camera (Phantom v7.1;Vision Research, NJ, USA) (as in Fig. 9.5). All the micro-channels were placed on the stage of the microscope where the flow rate of the working fluid was kept constant using a syringe pump (KD Scientific Inc., Holliston, MA, USA). A thermo-plate controller (Tokai Hit, Shizuoka, Japan) was also used: this achieved a surrounding temperature around the micro-channel of about $37^{\circ} \mathrm{C}$. More detailed information about this system can be found elsewhere [23,24,27,28].

All the measurements were digitised and transferred to a computer for evaluation using Phantom camera control software (PH607). The PIV images of the flowing particles were processed and the flow velocity was determined using the crosscorrelation PIV method (PivView). A full description and evaluation of the confocal micro-PIV system used in our studies can be found in Lima et al. [23]. For the case of the confocal micro-PTV measurements, series of confocal images were evaluated in Image J [3] using the manual tracking MtrackJ [38] plug-in. Generally, the motions of the labelled RBCs were manually tracked through successive images using the bright centroid criteria available at the MtrackJ. Using this method, it was possible to track labelled RBCs even when two cells were in close proximity. After obtaining a series of $x$ and $y$ positions, data were exported for the determination of several physical quantities such as velocity, radial displacement, and dispersion coefficient.

\subsubsection{Confocal Micro-PIV Results}

ig fluids ro blood to $20 \%$. working ; Het of particles iption of

kinds of ate glass $3,25,31]$. tangular
The ability of a confocal micro-PIV system to measure both pure water and diluted suspensions of RBCs was demonstrated by Lima et al. [23]. This study was performed with a square glass micro-channel and it was found that there was good agreement between the measured velocity profiles of pure water and an established analytical solution. Further work was performed by Lima et al. this time to measure both physiological saline (PS) and in vitro blood $(20 \% \mathrm{Hct})$ in a rectangular PDMS micro-channel [27]. As expected for a long rectangular microchannel, the velocity profiles were markedly smooth and flat in the centre of the micro-channel (as in Fig. 9.7). However, for the in vitro blood with $20 \%$ Hct, small fluctuations in the shape of the ensemble velocity profiles were observed (see Fig. 9.7). Possible reasons for these fluctuations are the interactions between neighbouring $\mathrm{RBCs}$, the formation of a cell-free layer, abrupt increase in the 


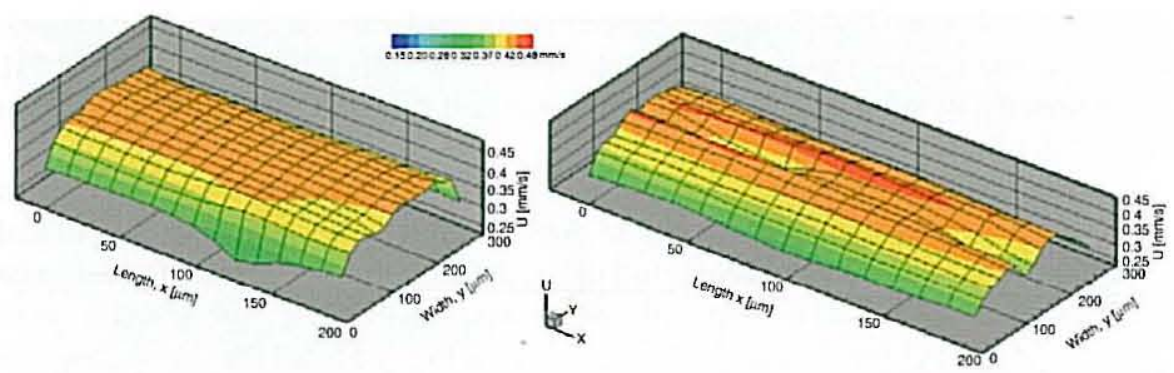

Fig. 9.7 Ensemble velocity profiles with PS (left image) and in vitro blood $20 \%$ Hct (right image) in a rectangular PDMS micro-channel (from [27])

shear rate in the vicinity of the wall, Hct temporal variation and the light scattered and absorbed from the RBCs.

Lima and his colleagues have performed another study to measure both ensemble and instantaneous velocity profiles for in vitro blood (Hct up to $17 \%$ ) flowing through a $100-\mu \mathrm{m}$ square micro-channel [25]. All the measurements were made in the middle plane at a constant flow rate and low Reynolds number $(\operatorname{Re}=0.025)$. Although the ensemble velocity profiles were markedly parabolic, some fluctuations in the instantaneous velocity profiles were found to be closely related to the Hct increase. This study has also shown strong evidence that the Root Mean Square (RMS) increases with the Hct increase suggesting that the concentration of RBCs within the plasma flow strongly influences the measurements of the instantaneous velocity fields. Possible reasons for the RMS increase are the motion and interaction of RBCs and the light scattered and absorbed by the RBCs. This latter behaviour seems to be predominant at an Hct value of about $17 \%$. More detailed information about these results can be found in Lima et al. [25].

\subsubsection{Confocal Micro-PTV Results}

Confocal micro-PIV experiments have shown the ability to measure with good accuracy in vitro blood with Hct up to $9 \%$, in a $100-\mu \mathrm{m}$ square micro-channel. However, for Hct bigger than $9 \%$, the light absorbed by the RBCs contributes to diminishing the concentration of tracer particles in the recorded confocal images. The low density images become more evident for Hct bigger than $20 \%$, which generates spurious errors in the velocity fields [25]. Therefore, Lima and his colleagues $[24,26,28]$ have applied a new approach, known as confocal microPTV, to track the trajectories of individual labelled RBCs at high Hcts. Figures 9.8 and 9.9 show the ability of this confocal method to measure the motion of blood cells at both diluted $(3 \% \mathrm{Hct})$ and high $(20 \% \mathrm{Hct})$ suspensions of RBCs, respectively. Additionally, successful measurements were performed in a $75-\mu \mathrm{m}$ circular PDMS micro-channel as shown in Fig. 9.10. 


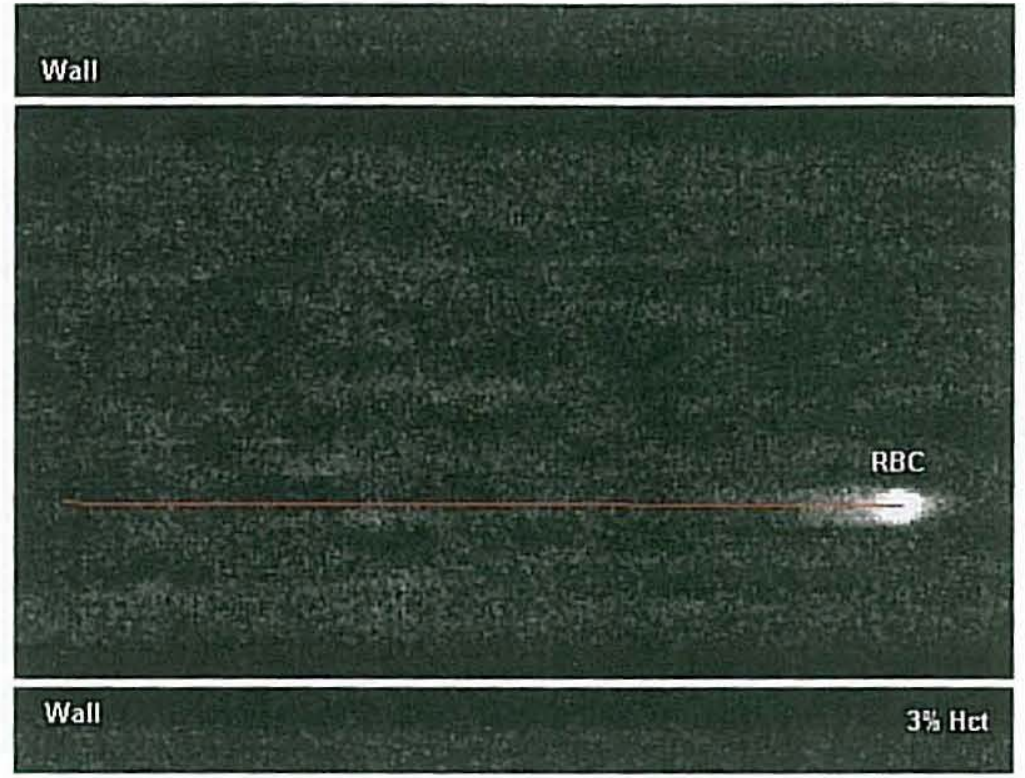

Fig. 9.8 Labelled RBC trajectory at diluted suspensions of cells (3\% Hct) obtained by the proposed confocal micro-PTV system (adapted from [26])

The ability of the confocal system to generate thin in-focus planes has allowed both qualitative and quantitative measurements in flowing blood at concentrated suspensions (up to $35 \% \mathrm{Hct}$ ) of: cell-cell hydrodynamic interaction, RBC orientation and $\mathrm{RBC}$ radial dispersion at different depths. Hence, to evaluate the capability of the confocal micro-PTV system to track RBCs, motions of labelled RBCs were followed at several Hcts $(3-37 \%)$. The measurements of complex microrheological events in flowing blood (such as interaction and orientation of blood cells) were performed near the wall of the micro-channel $(z=20 \mu \mathrm{m})$ with Hct $\sim 20 \%$ and $\operatorname{Re} \sim 0.007$.

\subsubsection{RBC-RBC Interactions in Flowing Blood}

The effect of hemodynamic interactions on the motion of RBCs depend on multi-physics factors, such as shear rate, deformability, plasma layer and wall constriction. Figure 9.11 shows the trajectories of two-RBC interactions close to the cell-free layer. This figure shows clearly the radial disturbance effect enhanced by the collision of a neighbouring $\mathrm{RBC}$. The radial displacement $(\triangle R)$ of the RBCs increases from two to six times of its initial radial displacement. For the case of $\mathrm{RBCl}, \Delta R$ continues to increase, due not only to the interaction above but also to others which may occur with neighbouring cells. 

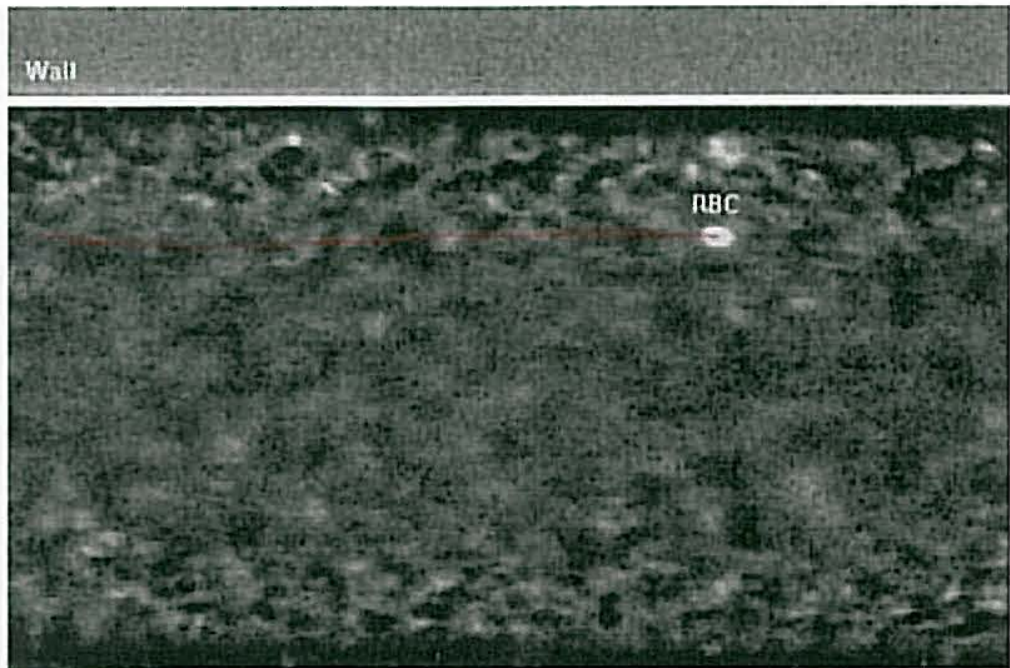

Fig. 9.9 Trajectory of a labelled RBC at high suspensions of cells (20\% Hct) obtained by the proposed confocal micro-PTV system. Experiments were carried out in glass micro-channels (adapted from [26])

\subsubsection{RBC-WBC Interactions in Flowing Blood}

The hemodynamic interaction effect of WBC on the motion of RBCs was also investigated by using confocal micro-PTV. Figure 9.12 shows the interaction of a $\mathrm{RBC}$ with the centre upper part of a WBC. Note that the RBC is located in the in-focus plane (high intensity) whereas part of the WBC is under the in-focus plane (lower intensity). It is possible to observe that transversal RBC displacement tends to increase when a collision occurs with a neighbouring WBC.

\subsubsection{Translational and Rotational Motion of RBCs}

The orientation of RBCs was extensively studied at low Hct (values $<1 \%$ ), but this behaviour differed from that for moderate and high Hcts. Figures 9.13 and 9.14 show the orientation of a $\mathrm{RBC}$ without and with an interaction, for flow close to the wall of a glass micro-channel. By adjusting the image contrast, it was possible to quantify both translational and rotational motion. The translational motion was measured at the centre of the $\mathrm{RBC}$ whereas the rotational was measured along the membrane: these are as shown in Figs. 9.13 and 9.14. The RBC motion without interaction (Fig. 9.13) was measured along the wall of the micro-channel. This RBC did not suffer any interaction with a neighbouring $\mathrm{RBC}$ so that its translational radial displacement was almost constant: as a result the $\mathrm{RBC}$ rotates as a biconcave 


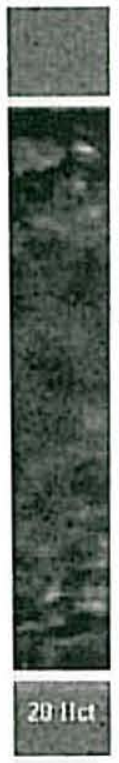

btained by the nicro-channels

Cs was also sraction of a cated in the -focus plane ement tends

$\%)$, but this 13 and 9.14 close to the . possible to motion was :d along the ion without 1. This RBC ranslational a biconcave
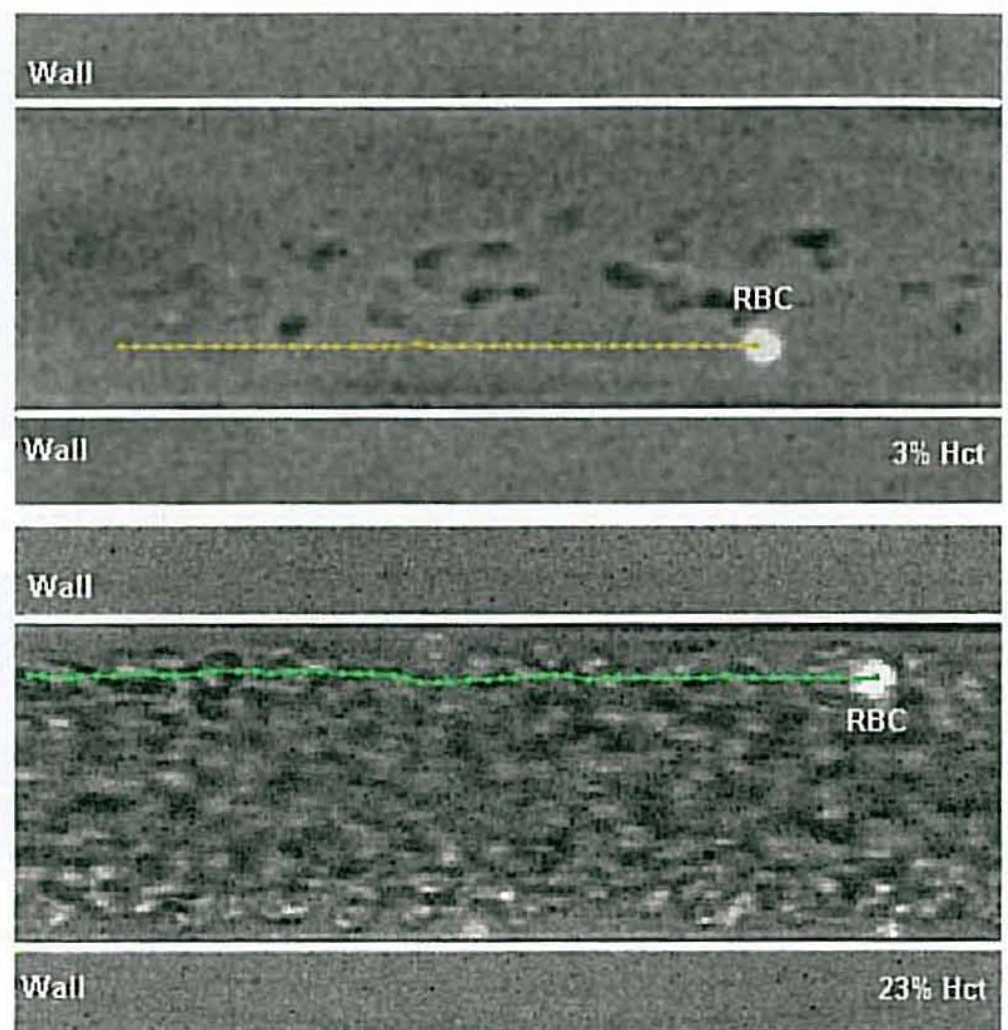

Fig. 9.10 Trajectory of labelled RBCs at low $(3 \% \mathrm{Hct})$ and high suspensions of RBCs $(23 \% \mathrm{Hct})$ obtained by the proposed confocal micro-PTV system. Experiments were carried out in circular PDMS micro-channel (adapted from [29])
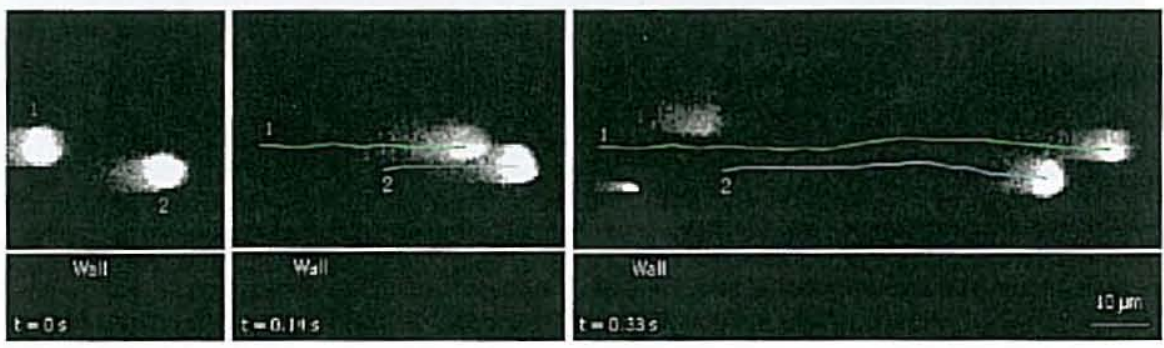

Fig. 9.11 Two-RBC interactions at different time intervals (adapted from [28])

disc in a clockwise direction with periodically varying angular velocity. By contrast, for RBCs that interact with neighbouring cells (Fig. 9.14) both translational and rotational motions change dramatically. In this case the rotation of the $\mathrm{RBC}$ is no longer regular and periodic but rather in an erratic manner. 


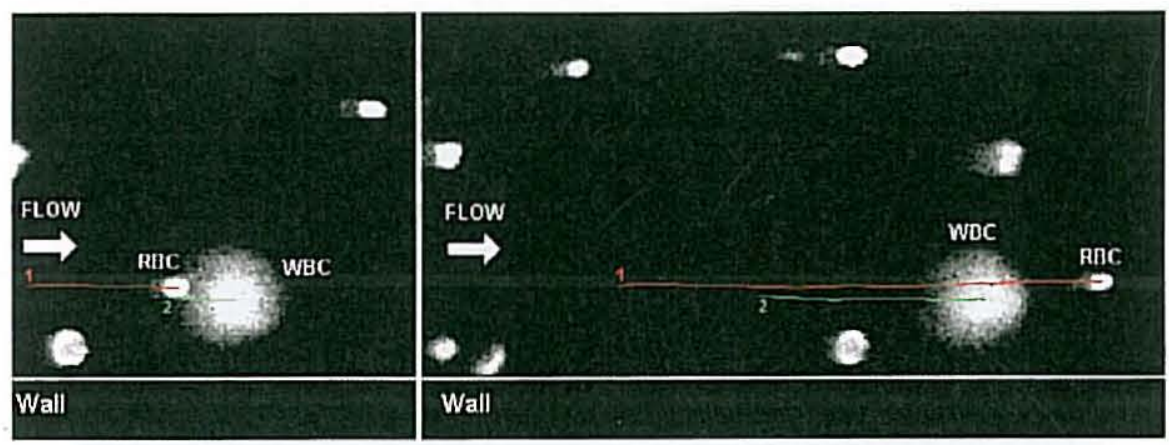

Fig. 9.12 Lateral RBC-WBC interaction at different time intervals (adapted from [32])

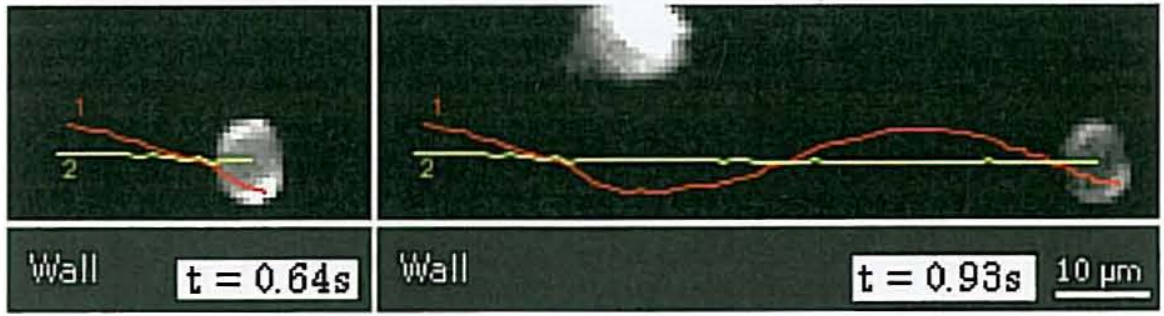

Fig. 9.13 Translational and rotational motion of a $\mathrm{RBC}$ rolling on the wall without interaction (adapted from [28])

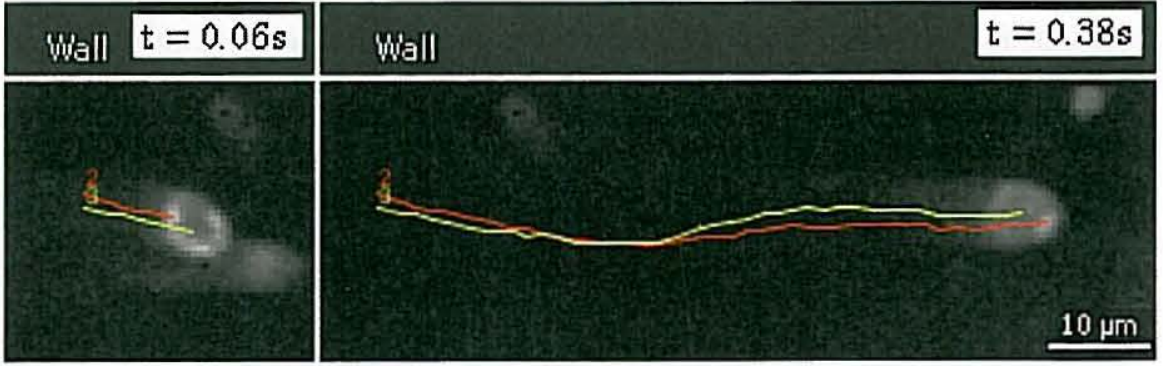

Fig. 9.14 Translational and rotational motion of RBC with interaction (adapted from [28])

\subsubsection{Effect of Het on RBC Radial Dispersion}

The randomlike transverse motions of RBCs can be analysed by using a radial dispersion coefficient $\left(D_{y y}\right)$, given by:

$$
D_{y y}=\sum_{t=0}^{n} \frac{\left\langle\left(R_{y}(t)-R_{y}(0)\right)^{2}\right\rangle}{2 t}
$$




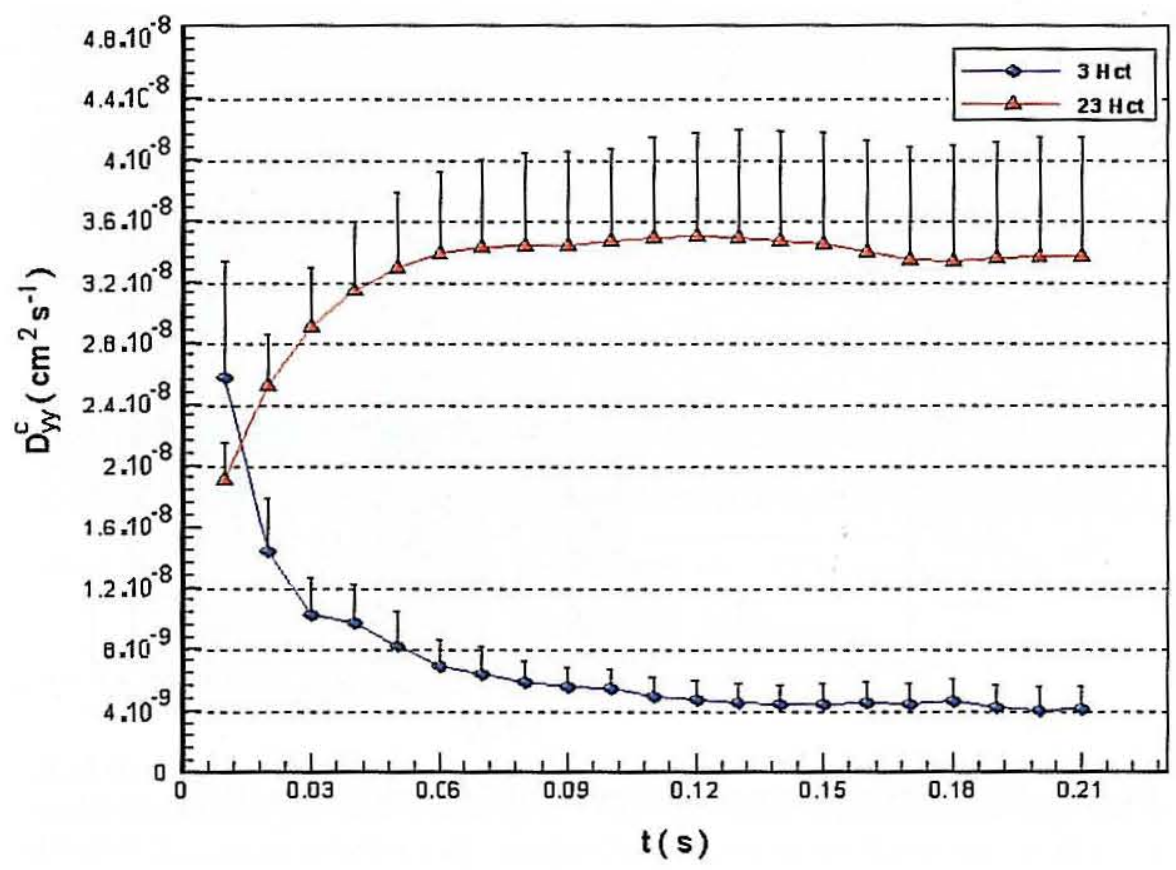

Fig. 9.15 RBCs radial dispersion coefficient $\left(D_{y y}\right)$ of $75 \mu \mathrm{m}$ PDMS circular micro-channel for $3 \%$ Hct and $23 \%$ Hct (adapted from [29])

where $R_{y}$ and t are the radial displacement and time interval respectively. Hence, in vitro blood with several Hcts was used, the confocal micro-PTV system enabling the paths of hundreds of labelled RBCs to be recorded in the centre plane of 100 and $50 \mu \mathrm{m}$ glass capillaries and $75 \mu \mathrm{m}$ PDMS circular micro-channels. The results demonstrated that for RBCs the $D_{y y}$ tends to increase with increasing Hct (as shown in Figs. 9.15 and 9.16). For instance Fig. 9.15 shows clearly that RBCs $D_{y y}$ at Hct of $23 \%$ is almost one order magnitude bigger than $D_{y y}$ with $3 \%$ Hct.

These research findings are evidence that the RBCs flowing in a crowded environment tend to undergo multi-body collisions which increase the amplitude of the RBC's lateral motion and consequently RBC $D_{y y}$. Hence, RBCs at high concentrations tend to exhibit higher erratic radial displacement compared to dilute suspensions of RBCs. Additionally, results given in Fig. 9.16 demonstrate that RBC radial dispersion, at both moderate and high Hcts, tends to decrease with the diameter. The main reasons for this are as follows: Hct reduction with diameter (Faharaeus effect) and the constrictive effect of the geometry, the latter limiting the amplitude of the radial displacements of the RBCs. Additional detailed results relating to these data can be found elsewhere $[26,28,29]$.

Very recently, in a study performed by Saadatmand et al. [37] fluid particle diffusion was examined in concentrated suspensions of human RBCs (Hct up to 20\%) through a 


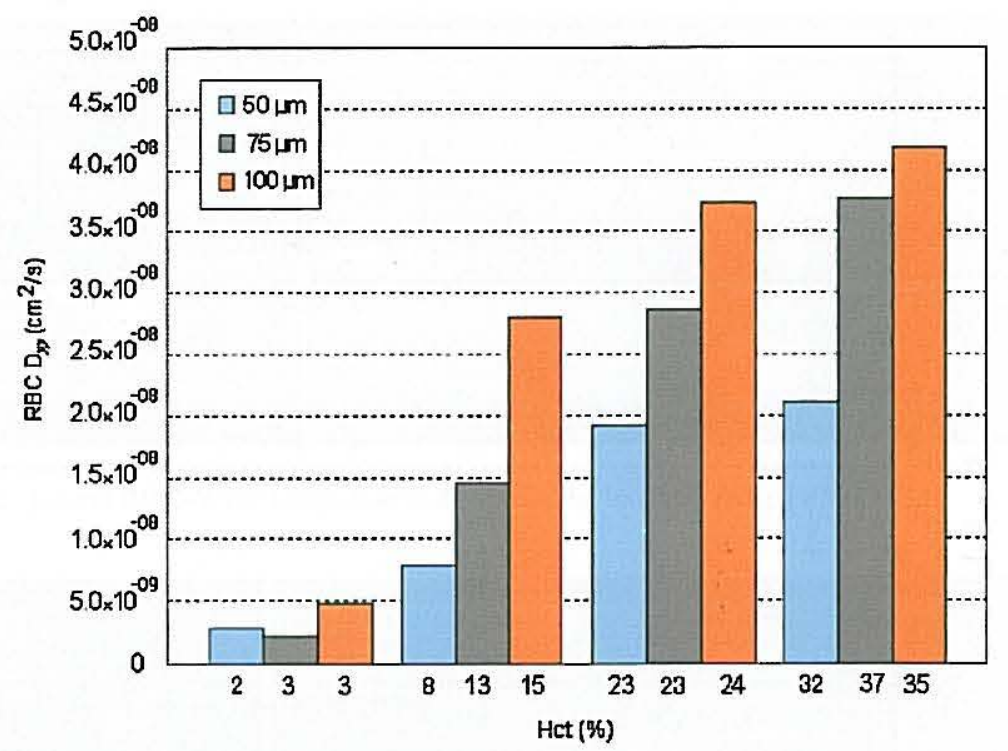

Fig. 9.16 Effect of the microtube geometry on the RBC $D_{y y}^{c}$ (adapted from [29])

capillary tube. The results demonstrated significant enhancement of the particle diffusion, due to a micron-scale flow-field generated by the RBC motions, whereas the dispersion of tracer particles was about 0.7 times that of RBCs. The results also showed that by increasing the flow rate particle dispersion tends to increase almost linearly under constant Hct levels. Moreover, the particle dispersion showed near linear dependency on Hct up to $20 \%$.

\subsubsection{Effect of Hct on the Cell-free Layer (CFL)}

Recent studies have investigated the Hct effect on the cell-free layer (CFL) thickness of both straight circular glass and PDMS micro-channels $[8,10,33]$. Labelled RBCs flowing near the CFL were tracked manually by using the MtrackJ plugin from Image J. Figure 9.17 gives an example of two trajectories of labelled RBCs flowing at the edge of the CFL. By using MtrackJ, the positions of the tracked RBCs are measured and the average thickness of the CFL is calculated $[8,10,30,33]$.

Examination of Fig. 9.18 reveals an overall enhancement of the CFL thickness as Hct decreases. For the case of the PDMS micro-channel, the CFL thickness decreases almost four fold as Hct is increased from 3 to $37 \%$ [30,33]. The results are clear evidence that the CFL thickness tends to reduce as the diameter of the microchannel decreases. 


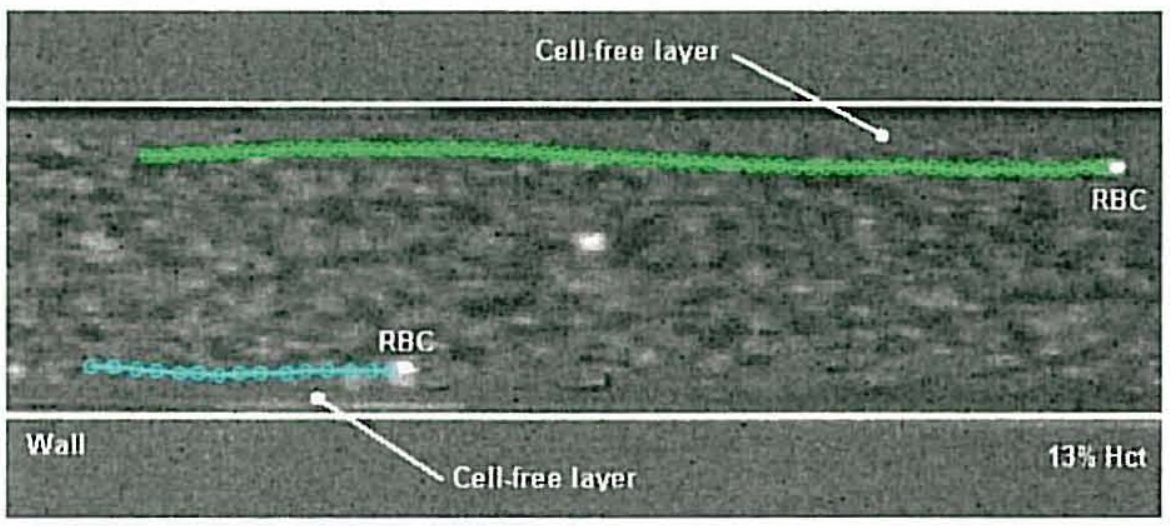

Fig. 9.17 Trajectory of labelled RBCs flowing nearby the cell-free layer (adapted by [29])

le diffureas the showed linearly r depen-

.) thickabelled I plugin 1 RBCs d RBCs i3]. ickness ickness iults are micro-

\subsubsection{In Vitro Blood Flow Through Complex Geometries}

Past studies on blood flow through glass micro-channels and in micro-vessels have yielded conflicting results with respect to flow resistance and deformability of RBCs $[42,48]$. However, observed in vivo/in vitro discrepancies have not yet been convincingly explained by the research, which is restricted to straight rigid glass microchannels. One possible way of understanding observed in vivo/in vitro discrepancies is by using PDMS micro-channels fabricated by a soft lithographic technique [27,34]. By using this kind of technique it is possible to fabricate biomimetic PDMS micro-channels with complex geometries similar to human blood arterioles and capillary networks. In a very recent study performed by Leble et al. [20-22] the effects were investigated of bifurcations (diverging and converging) on the flow behaviour of both fluorescent particles suspended in pure water (PW) and RBCs in concentrated suspensions ( $14 \% \mathrm{Hct}$ ). A very dominant phenomenon was observed in blood flow behaviour at the region of the converging bifurcation apex. At this region, the formation of a clear triangular CFL was observed, the layer tending to propagate along the centre of the micro-channel. Ishikawa et al. [17] and Leble et al. ([20-22], 2012) give more detailed information about this phenomenon.

Recently, Fujiwara et al., by using a confocal micro-PTV system have investigated the flow behaviour of RBCs in a micro-channel with a stenosis [11]. The influence of a stenosis $(70 \%)$ on the trajectories of individual RBCs was investigated in a concentrated suspension of up to $20 \%$ Hct. For $10 \%$ Hct the results indicated that healthy RBC trajectories have a tendency to become asymmetric before and after the stenosis whereas trajectories of particles suspended in pure water tend to be almost symmetric. Furthermore, the influence of the deformability of RBCs on the CFL thickness was also investigated. Fujiwara et al. have demonstrated that deformability plays a crucial role on the asymmetry of the CFL thickness. Generally, they have concluded that the motions of RBCs are strongly influenced not only by RBC deformability but also by the Hct and channel geometry [11]. 
Fig. 9.18 Average thickness of the cell-free layer at different Hcts and diameters $[30,33]$

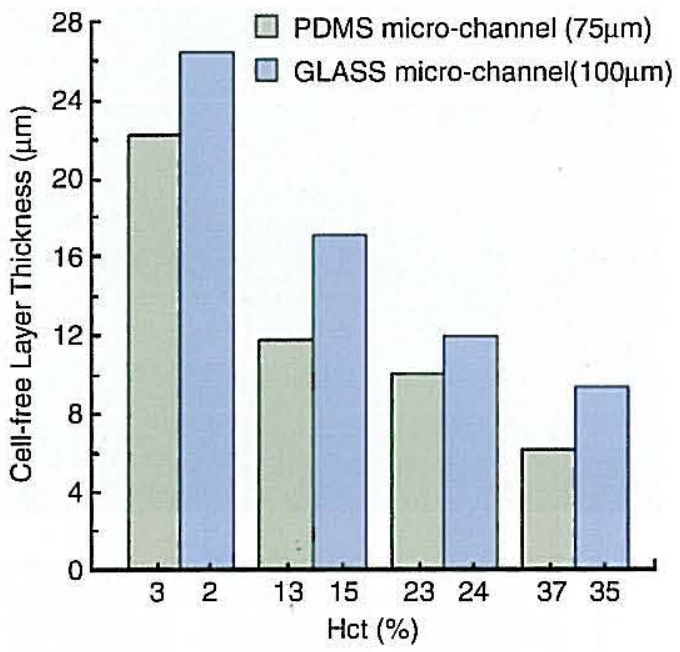

\subsection{Conclusion and Future Directions}

The recent developments in computing, digital image processing techniques and microscopy have made it possible to combine both particle image velocimetry (PIV) and particle tracking velocimetry (PTV) system with confocal microscopes, in so-called confocal micro-PIV/PTV. In this chapter we have presented the most relevant aspects of research using this approach: the theoretical and technical issues for both conventional and confocal micro-PIV/PTV methods and hemodynamic studies in micro-channels are facilitated by using systems based on these methods.

By using a $100-\mu \mathrm{m}$ square micro-channel, the confocal micro-PIV system has shown good accuracy in measuring blood plasma flow with Hct up to $9 \%$. Nevertheless, for Hct higher than $9 \%$, the light absorbed and scattered by the RBCs contributes to a diminution of the concentration trace particles and as a consequence generates spurious errors in the velocity profiles. This effect becomes much more evident for Hct above $20 \%$. Owing to its optical sectioning ability and consequent improvement of the image contrast and definition, a confocal microPTV system was then proposed to track individual blood cells at both low and high Hcts. By using such a system it was indeed found possible to measure cell-cell hydrodynamic interaction, $\mathrm{RBC}$ orientation and $\mathrm{RBC}$ radial dispersion at different depths and Hcts. Generally, the results suggest that the RBC paths are strongly dependent on the Hct and therefore the RBC dispersion coefficient tends to increase with increase in Hct. In addition, the confocal micro-PTV system has proved to be a powerful tool to obtain further insight into the flow behaviour of blood through complex geometries such as bifurcations, confluences and stenoses. Moreover, by culturing endothelial cells within PDMS microfluidic devices, we expect to develop in the near future a flow system device that closely mimics the in vivo micro-vessel environment. 
Acknowledgements The authors acknowledge the financial support provided by: International Doctoral Program in Engineering, from the Ministry of Education, Culture, Sports, Science and Technology of Japan (MEXT), 2007 Global COE Program "Global Nano-Biomedical Engineering Education and Research Network", Japan. Grant-in-Aid for Science and Technology (PTDC/ SAU-BEB/108728/2008, PTDC/SAU-BEB/105650/2008 and PTDC/EME-MFE/099109/2008) from the Science and Technology Foundation (FCT) and COMPETE, Portugal. The authors would also like to thank all the colleagues and students for their valuable comments, suggestions and technical assistance throughout this research work.

\section{References}

1. Adrian R (1991) Particle-imaging techniques for experimental fluid mechanics. Annu Rev Fluid Mech 23:261-304

2. Alonso C, Pries A, Kiesslich O, Lerche D, Gaehtgens P (1995) Transient rheological behaviour of blood in low-shear tube flow: velocity profiles and effective viscosity. Am J Physiol 268: $\mathrm{H} 25-\mathrm{H} 32$

3. Abramoff M, Magelhaes P, Ram S (2004) Image processing with image J. Biophotonics Int 11:36-42

4. Baker M, Wayland H (1974) On-line volume flow rate and velocity profile measurement for blood in microvessels. Microvasc Res 7:131-143

5. Born G, Melling A, Whitelaw J (1978) Laser Doppler microscope for blood velocity measurement. Biorheology 15:163-172

6. Bugliarello G, Hayden J (1963) Detailed characteristics of the flow of blood in vitro. Trans Soc Rheol 7:209-230

7. Cochrane T, Earnshaw J, Love A (1981) Laser Doppler measurement of blood velocity in microvessels. Med Biol Eng Comput 19:589-596

8. Cerdeira T (2009) Estudo do escoamento sanguíneo em microcanais. Final year project, Instituto Politécnico de Bragança (IPB), Portugal (in Portuguese)

9. Einav S, Berman R, Fuhro P, DiGiovanni P, Fine S, Fridman J (1975) Measurement of velocity profiles of red blood cells in the microcirculation by laser Doppler anemometry (LDA). Biorheology 12:207-210

10. Fidalgo $C$ (2010) Estudo da formaçāo da camada de plasma em microcanais. Final year project, Instituto Politécnico de Bragança (IPB), Portugal (in Portuguese)

11. Fujiwara $H$, Ishikawa $T$, Lima R, Marsuki N, Imai Y, Kaji H, Nishizawa M, Yamaguchi T (2009) Red blood cell motions in a high hematocrit blood flowing through a stenosed microchannel. J Biomech 42:838-843

12. Gaehtgens $P$, Meiselman H, Wayland $H(1970)$ Velocity profiles of human blood at normal and reduced hematocrit in glass tubes up to $130 \mu \mathrm{m}$ diameter. Microvasc Res 2:13-23

13. Goldsmith H (1971) Red cell motions and wall interactions in tube flow. Fed Proc 30 (5): $1578-1588$

14. Goldsmith H (1971) Deformation of human red cells in tube flow. Biorheology 7:235-242

15. Goldsmith H, Marlow J (1979) Flow behavior of erythrocytes II. Particles motions in concentrated suspensions of ghost cells. J Colloid Interface Sci 71(2):383-407

16. Golster H, Linden M, Bertuglia S, Colantuoni A, Nilsson G, Sjoberg F (1999) Red blood cell velocity and volumetric flow assessment by enhanced high-resolution laser Doppler imaging in separate vessels of hamster cheek pouch microcirculation. Microvasc Res 58:62-73

17. Ishikawa T, Fujiwara H, Matsuki N, Yoshimoto T, Imai Y, Ueno H, Yamaguchi T (2011) Asymmetry of blood flow and cancer cell adhesion in a microchannel with symmetric bifurcation and confluence. Biomed Microdevices 13:159-167 
18. Kim GB, Lee SJ (2006) X-ray PIV measurements of blood flows without tracer particles. Exp Fluids 41:195-200

19. Koutsiaris A, Mathioulakis D, Tsangaris S (1999) Microscope PIV for velocity-field measurement of particle suspensions flowing inside glass capillaries. Meas Sci Technol 10:1037-1046

20. Leble V, Dias R, Lima R, Fernandes C, Ishikawa T, Imai Y, Yamaguchi T (2011a) Motions of trace particles and red blood cells in a PDMS microchannel with a converging bifurcation. In: Yamaguchi T, Imai Y, Oliveira MSN, Lima R (eds) Japan-Portugal Nano-BME symposium: proceedings of the 2011 conference, Porto/Braganca, Portugal, pp 29-30

21. Leble V, Lima R, Fernandes C, Dias R (201 lb) Flow of red blood cells through a microchannel with a confluence. Proceedings of the Congresso de Métodos Numéricos em Engenharia 2011, CD-ROM paper ID267.pdf, Coimbra, Portugal.

22. Leble V, Lima R, Dias R, Femandes C, Ishikawa T, Imai Y, Yamaguchi T (2011c) Asymmetry of red blood cell motions in a microchannel with a diverging and converging bifurcation. Biomicrofluidics 5:044120

23. Lima R, Wada S, Tsubota K, Yamaguchi T (2006) Confocal micro-PIV measurements of three dimensional profiles of cell suspension flow in a square microchannel. Meas Sci Technol 17:797-808

24. Lima R (2007) Analysis of the blood flow behavior through microchannels by a confocal micro-PIV/PTV system. PhD (Eng), Bioengineering and Robotics Department, Tohoku University, Sendai, Japan

25. Lima R, Wada S, Takeda M, Tsubota K, Yamaguchi T (2007) In vitro confocal micro-PIV measurements of blood flow in a square microchannel: the effect of the haematocrit on instantaneous velocity profiles. J Biomech 40:2752-2757

26. Lima R, Ishikawa T, Imai Y, Takeda M, Wada S, Yamaguchi T (2008) Radial dispersion of red blood cells in blood flowing through glass capillaries: role of heamatocrit and geometry. J Biomech 44:2188-2196

27. Lima R, Wada S, Tanaka S, Takeda M, Ishikawa T, Tsubota K, Imai Y, Yamaguchi T (2008) In vitro blood flow in a rectangular PDMS microchannel: experimental observations using a confocal micro-PIV system. Biomed Microdevices 10(2):153-167

28. Lima R, Ishikawa T, Imai Y, Takeda M, Wada S, Yamaguchi T (2009a) Measurement of individual red blood cell motions under high hematocrit conditions using a confocal microPTV system. Ann Biomed Eng 37(8):1546-1559

29. Lima R, Nakamura M, Omori Y, Ishikawa T, Wada S, Yamaguchi T (2009b) Microscale flow dynamics of red blood cells in microchannels: an experimental and numerical analysis. In: Tavares, Jorge (eds) Advances in computational vision and medical image processing: methods and applications, vol. 13. Springer, pp 203-220

30. Lima R, Oliveira M, Cerdeira T, Monteiro F, Ishikawa T, Imai Y, Yamaguchi T (2009c) Determination of the cell-free layer in circular PDMS microchannels. ECCOMAS thematic conference on computational vision and medical image processing, Porto, Portugal

31. Lima R, Oliveira MSN, Ishikawa T, Kaji H, Tanaka S, Nishizawa M, Yamaguchi T (2009d) Axisymmetric PDMS microchannels for in vitro haemodynamics studies. Biofabrication 1(3):035005

32. Lima R, Ishikawa $\mathrm{T}$, Imai $\mathrm{Y}$ Yamaguchi $\mathrm{T}$ (2010a) Confocal micro-flow visualization of blood cells. Paper 1626. In: Pereira JCF, Sequeira A (Eds) Proceedings of fifth European conference on computational fluid dynamics, ECCOMAS CFD 2010, 14-17 June 2010, Lisbon, Portugal

33. Lima $\mathrm{R}$ et al (2010b) Measuring the cell-free layer in circular microchannels. Proceedings of the Sixth World Congress of biomechanics, Singapore

34. Lima R, Fernandes C, Dias R, Ishikawa T, Imai Y, Yamaguchi T (2011) Microscale flow dynamics of red blood cells in microchannels: an experimental and numerical analysis, In: Tavares, Jorge (eds) Computational vision and medical image processing: recent trends, vol. 19 Springer, pp 297-309

35. Lima R, Dias R, Leble V, Fernandes C, Ishikawa T, Imai Y, Yamaguchi T (2012) Flow visualization of trace particles and red blood cells in a microchannel with a diverging and 
ticles. Exp

1 measure-

1037-1046

Motions of rcation. In: rmposium:

zrochannel jaria 2011,

Isymmetry ifurcation.

ats of three zi Technol

a confocal hoku Uni-

micro-PIV latocrit on

sion of red geometry.

1i T (2008) ms using a נrement of cal micro-

sscale flow ralysis. In: rocessing:

$\mathrm{T}(2009 \mathrm{c})$

$S$ thematic I

T (2009d)

fabrication

on of blood conference $\mathrm{n}$, Portugal :eedings of

sscale flow 1 analysis, ent trends,

012) Flow erging and converging bifurcation. ECCOMAS thematic conference on computational vision and medical image processing, Olhão, Portugal, pp 209-211

36. Lima R, Ishikawa T, Imai Y, Yamaguchi T (2012) Blood flow behavior in microchannels: advances and future trends. In: Dias et al (eds) Single and two-Phase flows on chemical and biomedical engineering, Bentham Science Publishers, Springer (in press)

37. Saadatmand M, Ishikawa T, Matsuki N, Abdekhodaie MJ, Imai Y, Ueno H, Yamaguchi T (2011) Fluid particle diffusion through high-hematocrit blood flow within a capillary tube. J Biomech 44:170-175

38. Meijering E, Smal I, Danuser G (2006) Tracking in molecular bioimaging. IEEE Signal Process Mag 23:46-53

39. Meinhart C, Wereley S, Santiago J (1999) PIV measurements of a microchannel flow. Exp Fluids 27:414-419

40. Nakano A, Sugii Y, Minamiyama M, Niimi H (2003) Measurement of red cell velocity in microvessels using particle image velocimetry (PIV). Clin Hemorheol Microcirc 29:445-455

41. Parthasarathi A, Japee S, Pittman R (1999) Determination of red blood cell velocity by video shuttering and image analysis. Ann Biomed Eng 27:313-325

42. Pries A, Secomb T, Gessner T, Sperandio M, Gross J, Gaehtgens P (1994) Resistance to blood flow in microvessels in vivo. Circ Res 75:904-915

43. Tangelder G, Slaaf D, Muijtjens M, Arts T, Egbrink M, Reneman R (1986) Velocity profiles of blood platelets and red blood cells flowing in arteriols of rabbit mesentery. Circ Res 59:505-514

44. Sbalzarini IF, Koumoutsakos P (2005) Feature point tracking and trajectory analysis for video imaging in cell biology. J Struct Biol 151(2):182-195

45. Santiago J, Wereley S, Meinhart C, Beebe D, Adrian R (1998) A particle image velocimetry system for microfluidics. Exp Fluids 25:316-319

46. Sugii Y, Nishio S, Okamoto K (2002) In vivo PIV measurement of red blood cell velocity field in microvessels considering mesentery motion. Physiol Meas 23:403-416

47. Sugii Y, Okuda R, Okamoto K, Madarame H (2005) Velocity measurement of both red blood cells and plasma of in vitro blood flow using high-speed micro PIV technique. Meas Sci Technol 16:1126-1130

48. Suzuki Y, Tateishi N, Soutani M, Maeda N (1996) Deformation of erythrocytes in microvessels and glass capillaries: effects of erythrocyte deformability. Microcirculation 3:49-57

49. Uijttewaal W, Nijhof E, Heethaar R (1994) Lateral migration of blood cells and microspheres in two-dimensional Poiseuille flow: a laser Doppler study. J Biomech 27:35-42

50. Vennemann P, Kiger K, Lindken R, Groenendijk B, Stekelenburg-de Vos S, Hagen T, Ursem N, Poelmann RE, Westerweel J, Hierk B (2006) In vivo micro particle image velocimetry measurements of blood-plasma in the embryonic avian heart. J Biomech 39:1191-1200

51. Wereley ST, Meinhart CD (2010) Recent advances in micro-particle image velocimetry. Annu Rev Fluid Mech 42:557-576

52. Yaginuma T, Oliveira MSN, Lima R, Dias R, Ishikawa T, Imai Y, Yamaguchi T (2012) Flow visualization of trace particles and red blood cells in a microchannel with a diverging and converging bifurcation, ECCOMAS thematic conference on computational vision and medical image processing, Olhāo, Portugal, pp 209-211

53. Yaginuma T, Oliveira MSN, Lima R, Ishikawa T, Yamaguchi T (2011) Red blood cell deformation in flows through a PDMS hyperbolic microchannel. In: Proceedings of TechConnect World 2011-Microtech Conference and Expo 2011, Boston, MA, USA, 2, 505 